\title{
Prevalence of myopia and its socio-demographic distribution amongst secondary school going adolescents in Lurambi Sub-County, Kakamega, Kenya
}

\author{
Alfred Ragot ${ }^{1}$, Mustafa Baraza' ${ }^{2}$, Peter Clarke-Farr ${ }^{3}$ \\ ${ }^{1}$ Department of Optometry and Vision Science, School of Public Health and Biomedical Sciences, \\ Masinde Muliro University of Science and Technology, Kakamega, Kenya \\ ${ }^{2}$ Department of Medical Laboratory and Biotechnology, School of Public Health and Biomedical Sciences, \\ Masinde Muliro University of Science and Technology, Kakamega, Kenya \\ ${ }^{3}$ Department of Ophthalmic Sciences, Faculty of Health and Wellness Sciences, Cape Peninsula University of Technology, \\ Cape Town, South Africa
}

\begin{abstract}
BACKGROUND: Globally the prevalence of myopia has increased alarmingly and is expected to affect an estimated 2.56 billion people in the world by the end of 2020. It is believed to be the leading cause of visual impairment in Kenya, contributing $59.5 \%$ of all causes of visual impairment. Still, agreement on the exact prevalence in Kenya and whether socio-demographic factors have an influence on myopia is unknown.

This study was aimed at evaluating the prevalence of myopia and its socio-demographic distribution amongst randomly selected school-going adolescent.

This study was conducted in Lurambi Sub-County in Kakamega, Kenya.

MATERIAL AND METHODS: The study adopted a school-based cross-sectional descriptive study design. Using a multi -stage sampling technique, 733 participants from a population of 7,400 secondary school students within Lurambi Sub-County were randomly selected. A standard optometric vision-assessment protocol was applied to those who met the inclusion criteria and cycloplegic refraction was conducted to elicit those who had myopia.

RESULTS: The prevalence of myopia was found to be $7.5 \%$ of which $29(52.7 \%)$ were male while $26(47.3 \%)$ were female and there was no association between gender and myopia $(\mathrm{p}=0.572)$. Myopia was found to be more prevalent in urban $49(87.3 \%)$ as compared to rural $7(12.7 \%)$ areas and there was no association between place of residences and myopia $(\mathrm{p}=0.381)$. Similarly, $15-18$ years was the dominant age group $39(70.9 \%)$ and there was no association between age and having myopia $(\mathrm{p}=0.926)$. The study also found that there was no association $(\mathrm{p}=0.207)$ between school class of the participants and having myopia, although most myopic cases were in the form four class 15 (27.3\%).

CONCLUSION: Myopia was found to be mostly prevalent in the urban setting and upper classes as compared to rural and lower classes. This may link myopia to other risk factors such as near work and outdoor activities, but more research needs to be done in these areas.
\end{abstract}

KEY WORDS: myopia; Kenya; prevalence; socio-demographic 


\section{INTRODUCTION}

Myopia is estimated to be the leading cause of visual impairment (VI) of all Uncorrected Refractive Error (URE) and it is believed to be the most common eye condition worldwide [1]. Nearly 1.89 billion people are myopic in the world [2], and this number is projected to rise to 2.56 billion by 2020 if nothing is done to address the situation [3]. Myopia is a public health problem worldwide [4], and it is one of the five ocular problems that have been identified by the World Health Organization as an immediate priority for the global initiative of preventable blindness [5]. Myopia and high myopia can result in other vision-threatening conditions like myopic macular degeneration, retinal detachment, cataract as well as choroid degenerative conditions [6]. The risk is comparable to the risk of smoking and hypertension to cardiovascular health [7]. Myopia has also been associated with poor socioeconomic status and quality of life [The prevalence of URE in Africa has been estimated to be 2.3\%, and that of myopia is not well documented [9]. In Kenya, studies on the prevalence of myopia and its risk factors are scarce. It is, however, believed to be the leading cause of visual impairment in Kenya and it contributes to $59.5 \%$ of refractive errors in Kenya [10]. Despite this, its exact prevalence is not well known.

\section{MATERIAL AND METHODS}

This study was conducted in secondary schools around Lurambi Sub-County, Kenya. Lurambi Sub-County is one of the most cosmopolitan sub-counties which is located in the western part of the country (Kenya), and it is inhabited by people from different parts of the country and different ethnic groups. A school-based cross-sectional study design was adopted. All participants that were selected were aged between 10 to 19 years. Significant myopia in this study was defined as myopia $\geq-0.50 \mathrm{D}$. In addition, the participant with defined myopia must present with Snellen Visual Acuity (VA) of $6 / 9$ or worse for distance VA in any eye, equivalent to 0.1 or worse logarithm of the minimum angle of resolution $(\log M A R)$. The multistage sampling technique took place in two stages as follows:

— stage one - this involved purposive sampling of two clusters. The 22 schools in Lurambi Sub -County were classified into two; urban schools and rural schools. The urban schools were identified by their locality. Those schools that were fo- und within Kakamega Municipality of Lurambi Sub-County were classified as urban schools and those that were found in the rural part of Lurambi Sub-County formed the second cluster which were rural schools. This was to ensure maximum coverage of all levels of socio-demographic and socio-economic features of the study area. The two clusters had a total of 22 secondary schools with students' enrolment having been estimated to be 7,400 in 2020 ;

— stage two - this involved a computer-generated random system in order to sample the schools. Since there was a disproportionate number of students in the schools, a proportionate sampling technique was employed to ensure that all the schools and every student in each cluster had an equal chance of being selected. To achieve this and considering that some schools had student populations as low as 25 while others had student population as high as 1500 , all the schools in the two clusters were shared into groups of near-equal student numbers. The grouping was based on an increasing additive order, and each of the groups were serially numbered. Using the computer-generated random system (http://www.random.org/integers/), two groups were selected for screening, one in the rural group and one in the urban group. The purpose of eye screening was to identify children with myopia and those with normal sight.

Free eye screening was conducted in each of the schools that formed part of the study in both rural and urban areas. The study population was subjected to visual acuity screening and all those who had visual acuity of 6/9 or worse in any of the two eyes qualified for the next stage of the examination. To avoid loss of school-time during the screening sessions, pre-arrangement was agreed upon with the school headteacher or principal for a make-up class for the children that were to be included in the study. Also, lunch plans to cater for extended hours for the children was provided in the study budget.

Permission was sought from the different authorities, namely the legal guardians of the children through the different school heads for each of the selected schools in the selected groups, the Sub-County education officers, and the county education officer before the commencement of the study. The final years optometry students were briefed on the research and they assisted in assessments and examination of the participants. Written informed consent/assent was obtained for all the adolescents 
or from the legal guardians. For minors, permission was sought through the headteacher before conducting a detailed assessment. Ethical approval was granted by the ethical review committee of Masinde Muliro University of Science and Technology and the approval letter is available upon request. The consent had the full content of the study. The assessment included the steps below.

\section{STEP 1}

Visual acuity testing was done with all participants that formed part of the study. Those having a visual acuity of $6 / 9$ or worse were subjected to the pinhole test to elicit if the refractive error was the reason for the reduced visual acuity. Those with visual acuity better than $6 / 6$ were classified as normal. The children and their teachers (for minors) presenting as their legal proxies were counselled on their identified visual condition. The children were also informed of the importance of their continued participation in the study. Those with minor allergies or infections were dispensed free of charge (on the study budget).

\section{STEP 2}

Children presenting with Snellen VA of 6/9 or worse in any of the eyes underwent direct ophthalmoscopy using Keeler professional direct ophthalmoscope, to rule out any non-refractive ocular pathology. If any pathology was found, these children were excluded from the study. However, the children were referred to either the Academic Vi-

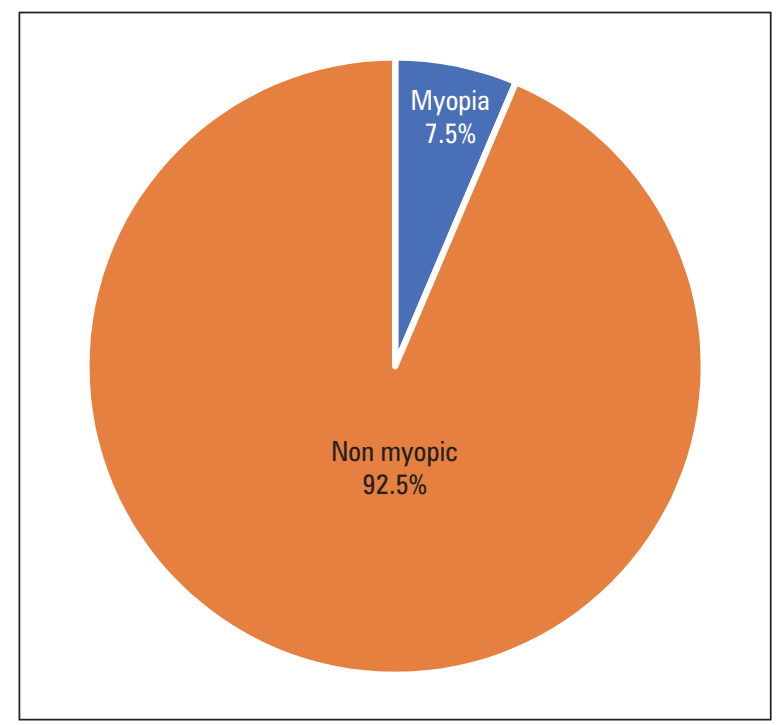

FIGURE 1. Prevalence of myopia sion Centre or Sabatia Eye Hospital (SEH) which is the only eye hospital in the western part of Kenya. If no pathology was found, children underwent cycloplegic refraction, and where cycloplegia was not possible, non-cycloplegic Mohindra retinoscopy was performed, using a Keeler streak retinoscope, to elicit if the refractive error was myopia, while controlling for accommodation. If the participants had any other refractive error apart from myopia and myopic astigmatism in which the spherical equivalent was calculated, the participants or their legal guardians were counselled on the need for spectacle correction. They were also then excluded from the study and were referred to MMUST Academic Vision Centre (AVC) for spectacle correction that was subsidized.

\section{STEP 3}

The basic socio-demographic data and contact details of the participants and their legal guardians were collected.

\section{RESULTS}

The current study sampled a total of 733 students, of whom 55 were found to be myopic giving an overall prevalence of $7.5 \%$ (Fig. 1). Of these students, 29 (52.7\%) were male while 26 (47.3\%) were female. Further details of the gender, domicile and age are presented in Table 1.

This study found the prevalence of myopia in males to be $29(4.0 \%)$ while that of females was found to be $26(3.5 \%)$. Myopia was found to be more prevalent in urban $49(6.7 \%)$ as compared to the rural $6(0.8 \%)$ schools (Tab. 4$)$.

\section{AGE AND MYOPIA}

Myopia was found to occur in the range from 14 to 19 years while the most dominant age of

\begin{tabular}{|l|l|c|c|}
\hline \multicolumn{5}{|c|}{ Table 1. Descriptive statistics for students } \\
\hline & & Frequency & Percent \\
\hline Gender & Female & 326 & 44.5 \\
\hline & Male & 407 & 55.5 \\
\hline Domicile & Rural & 383 & 52.3 \\
\hline & Urban & 349 & 47.6 \\
\hline Age & $11-14$ years & 60 & 8.2 \\
\hline & $15-18$ years & 520 & 70.9 \\
\hline & Above 18 years & 153 & 20.9 \\
\hline
\end{tabular}


Table 2. Distribution of myopia in terms of age

\begin{tabular}{|c|c|c|c|c|c|c|c|c|c|}
\hline & \multicolumn{7}{|c|}{ Age } & \multirow{2}{*}{ Total } \\
\hline & & 13.0 & 14.0 & 15.0 & 16.0 & 17.0 & 18.0 & 19.0 & \\
\hline \multirow{2}{*}{ Myopia } & Count & 0 & 3 & 7 & 15 & 12 & 9 & 9 & 55 \\
\hline & Percentage of total & $0.0 \%$ & $0.4 \%$ & $1.0 \%$ & $2.1 \%$ & $1.6 \%$ & $1.2 \%$ & $1.2 \%$ & $7.5 \%$ \\
\hline
\end{tabular}

Table 3. Magnitude of myopia distribution

\begin{tabular}{|c|c|c|c|}
\hline \multicolumn{1}{|c|}{ Magnitude of myopia } & Right eye n (\%) & Left eye n (\%) \\
\hline \multirow{4}{*}{ Myopia } & -10.00 & $1(1.8 \%)$ & $2(3.6 \%)$ \\
\cline { 2 - 4 } & -4.00 & $1(1.8 \%)$ & $1(1.8 \%)$ \\
\cline { 2 - 4 } & -3.75 & $1(1.8 \%)$ & $1(1.8 \%)$ \\
\cline { 2 - 4 } & -3.50 & $2(3.6 \%)$ & $3(5.5 \%)$ \\
\cline { 2 - 4 } & -3.25 & $2(3.6 \%)$ & $1(1.8 \%)$ \\
\cline { 2 - 4 } & -2.50 & $1(1.8 \%)$ & $1(1.8 \%)$ \\
\cline { 2 - 4 } & -2.25 & $1(1.8 \%)$ & $1(1.8 \%)$ \\
\cline { 2 - 4 } & -2.00 & $3(5.5 \%)$ & $3(5.5 \%)$ \\
\cline { 2 - 4 } & -1.75 & $1(1.8 \%)$ & $2(3.6 \%)$ \\
\cline { 2 - 4 } & -1.25 & $4(7.3 \%)$ & $3(5.5 \%)$ \\
\cline { 2 - 4 } & -1.00 & $5(9.1 \%)$ & $5(9.1 \%)$ \\
\cline { 2 - 4 } & -0.75 & $16(29.1 \%)$ & $16(29.1 \%)$ \\
\cline { 2 - 4 } & -0.50 & $16(29.1 \%)$ & $16(29.1 \%)$ \\
\cline { 2 - 4 } & -0.25 & $1(1.8 \%)$ & $0(0 \%)$ \\
\cline { 2 - 4 } & Total & $55(100 \%)$ & \\
\hline
\end{tabular}

those who had myopia was found to be 16 years $15(2.1 \%)$.

\section{MAGNITUDE OF MYOPIA}

About one third $16(29.1 \%)$, of the participants, had mild $(-0.50 \mathrm{D})$ myopia while $16(29.1 \%)$ had moderate myopia $(-0.75 \mathrm{D})$. One participant (1.8\%) had-10.00DS.

\section{SOCIAL-DEMOGRAPHIC DISTRIBUTION OF STUDY PARTICIPANTS}

The socio-demographic characteristics, as shown in Table 1 found no association between gender and myopia $(\mathrm{p}=0.572)$. Males constituted just over half of the study participants 29 (52.7\%). The 15-18-year group was the dominant age group and there was no association between age and myopia $(\mathrm{p}=0.926)$. In addition, most of the participants came from an urban setting 49 (87.3\%) although there was no association between place of residence and myopia $(\mathrm{p}=0.381)$.

There was no association between the school class group of the participants and having myopia $(p=0.207)$. Most of the participants who were myopic, were form four 15 (27.3\%) although there was an equal distribution of myopia in terms of the class of the respondents. A significant number of the parents of the respondents $24(43.6 \%)$ were unemployed and $39(70.9 \%)$ were married. While $23(41.8 \%)$ of the parents of the participants had primary and $22(40.0 \%)$ had secondary education qualifications, there were no significant differences between the highest level of education and myopia $(\mathrm{p}=0.283)$.

\section{DISCUSSION}

The overall prevalence of myopia in this study was found to be $7.5 \%$, which is a higher value compared to previous studies [11] of $1.7 \%$, [12] $5.6 \%$ and $1.7 \%$ of [13]. This can be attributed to the study population in this study as compared to other studies. It is well established that myopia is highly prevalent in adolescents as compared to other age groups (14). The high prevalence has been attributed to the eyeball elongation due to environmental factors such as near work and reduced outdoor activities [15].

Females and males in the study constituted 45\% and $55 \%$ respectively of the total of 733 students who participated in the study. Myopia was found to be only slightly more prevalent in males 29 (52.7\%) compared to females, $26(47.3 \%)$. The difference in prevalence among male and female was not significant $(\mathrm{p}=0.576)$. The study was concurrent with [11] that found that there was no statistically significant difference in the prevalence of myopia among females and males. Although a study by [13] found myopia to be slightly more prevalent in females compared to males at $1.8 \%$ and $1.7 \%$ respectively, the difference not to be statistically significant.

This study found that myopia was mostly prevalent in the age group of 15-18 years and the mean age of participants who were myopic was 16 years. This can be because of the eyeball elongation due to hereditary/familial or due to environmental or other causes that are related to the growth of the eye, specifical overgrowth of the eye and dis-correlation between axial length and cor- 


\begin{tabular}{|c|c|c|c|c|}
\hline Socio-demographic variable & & Myopia n (\%) & $\begin{array}{l}\text { Myopia percentage of total } \\
\text { sample }(n=733)\end{array}$ & $\mathrm{p}$ value \\
\hline \multirow[t]{2}{*}{ Gender } & Male & $29(52.7 \%)$ & $29(4.0 \%)$ & \multirow{2}{*}{0.576} \\
\hline & Female & $26(47.3 \%)$ & $26(3.6 \%)$ & \\
\hline \multirow[t]{3}{*}{ Age } & 11-14 Years & $5(9.1 \%)$ & $5(0.6 \%)$ & \multirow{3}{*}{0.926} \\
\hline & 15-18 Years & $39(70.9 \%)$ & $39(5.3 \%)$ & \\
\hline & Above 18 years & $11(20.0 \%)$ & $11(1.5 \%)$ & \\
\hline \multirow[t]{2}{*}{ Residence of the client } & Urban & $49(89.0 \%)$ & $49(6.7 \%)$ & \multirow{2}{*}{0.381} \\
\hline & Rural & $6(11.0 \%)$ & $6(0.8 \%)$ & \\
\hline \multirow[t]{4}{*}{ Current Class of The Respondent } & Form One & $15(27.3 \%)$ & $15(2.0 \%)$ & \multirow{4}{*}{0.207} \\
\hline & Form Two & $15(27.3 \%)$ & $15(2.0 \%)$ & \\
\hline & Form Three & $10(18.1 \%)$ & $10(1.4 \%)$ & \\
\hline & Form Four & $15(27.3 \%)$ & $15(2.0 \%)$ & \\
\hline \multirow[t]{4}{*}{ Parents'/Caregivers' occupation } & Self-Employed & $10(18.2 \%)$ & $10(1.4 \%)$ & \multirow{4}{*}{0.750} \\
\hline & Employed & $13(23.6 \%)$ & $13(1.8 \%)$ & \\
\hline & Unemployed & $24(43.6 \%)$ & $24(3.2 \%)$ & \\
\hline & Farming & $8(14.5 \%)$ & $8(1.1 \%)$ & \\
\hline \multirow[t]{3}{*}{ Parents' marital status } & Married & $39(70.9 \%)$ & $39(5.3 \%)$ & \multirow{3}{*}{0.507} \\
\hline & Divorced & $6(10.0 \%)$ & $6(0.8 \%)$ & \\
\hline & Separated & $10(18.2 \%)$ & $10(1.4 \%)$ & \\
\hline \multirow[t]{3}{*}{ Fathers' education level } & Primary & $23(41.8 \%)$ & $23(3.1 \%)$ & \multirow{3}{*}{0.283} \\
\hline & Secondary & $22(40.0 \%)$ & $22(3.0 \%)$ & \\
\hline & Tertiary & $10(18.2 \%)$ & $10(1.4 \%)$ & \\
\hline \multirow[t]{3}{*}{ Mothers' education level } & Primary & $22(40.0 \%)$ & $22(3.0 \%)$ & \multirow{3}{*}{0.283} \\
\hline & Secondary & $22(40.0 \%)$ & $22(3.0 \%)$ & \\
\hline & Tertiary & $11(10.0 \%)$ & $11(1.5 \%)$ & \\
\hline
\end{tabular}

Data are presented as frequencies $(\mathrm{n})$ and percentages $(\%)$, categorical variables were compared using Chi-square test. Significance set at $\mathrm{p}<0.05$

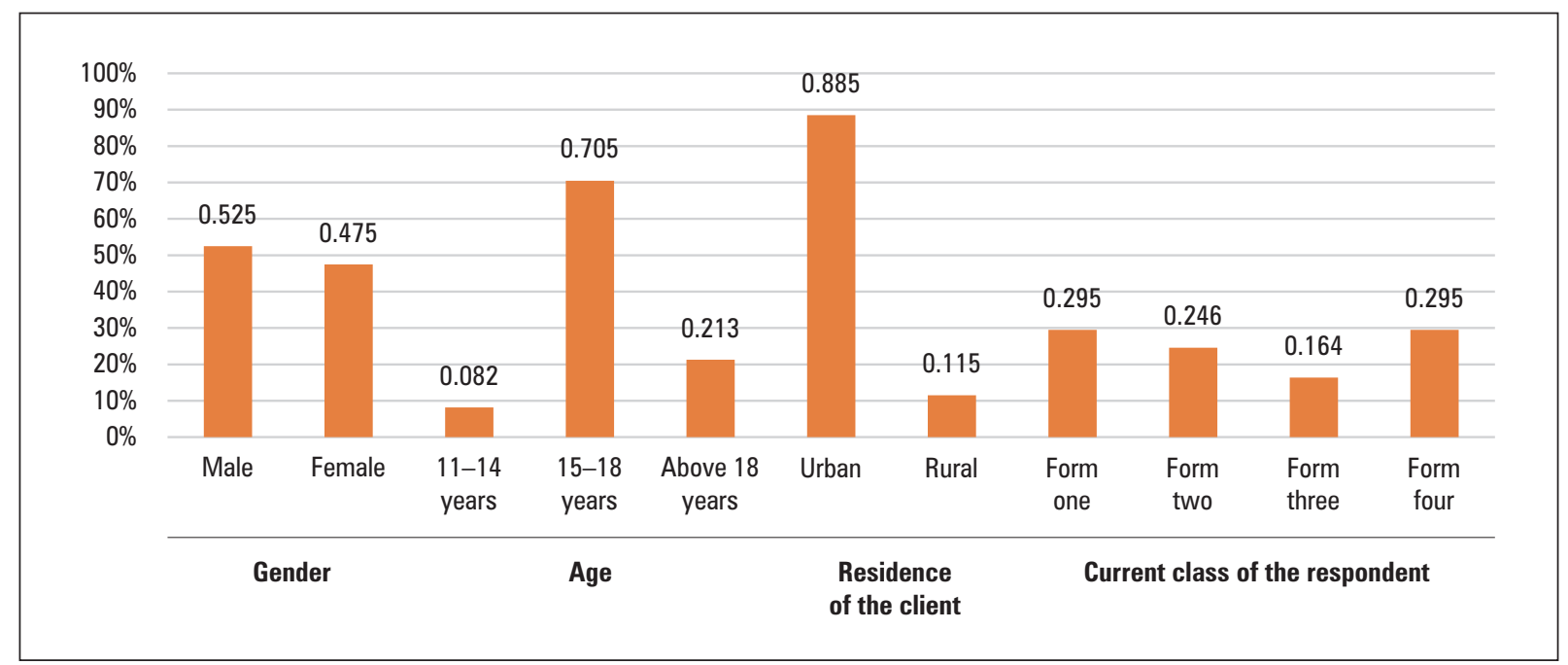

FIGURE 2. Student's socio-demographic factors cross-tabulation with myopia 
neal curvature soon after puberty [16]. The finding of this study is slightly different to [3] study that was conducted in Uganda of myopia being highly prevalent in 11-14 yearsMost of the study population came from the rural area since the Kakamega county setting is mostly rural. The urban setting is located in the square radius of 10 kilometers from the town center. Most secondary schools are also found in a rural area with few schools found in the urban area. This study found that myopia was mostly prevalent in students that come from urban areas $49(6.7 \%)$ compared to the students that come from rural areas $6(0.8 \%)$ even though the most domiciled area was a rural area. These results are similar to a recent study [17], that found a higher prevalence of myopia in urban areas compared to the rural areas. Another study by [18] found that the prevalence of childhood myopia was lowest $(6.9 \%)$ in the outer suburban region and highest (17.8\%) in the inner-city region. Although the comparison of the prevalence of myopia in the two settings is difficult due to the impact of other confounding factors such as education, schooling and outdoor activities, these factors make it difficult to entirely associate the difference with the urban or rural environments alone. One suggestion for the reason for the high prevalence of myopia in urban setting has been attributed to the rise in technology and the increased usage of mobile phones, tablets, computers and televisions, especially among children and youths. This and the reduction in outdoor activities have been found to have some influence on the onset, development and progression of myopia [19]. Children in urban settings, in this era, spend less time with outdoor activities unlike children in the 1980's and early 1990's. This is due to the lack of playing grounds since most of the areas that were set aside in urban areas as children playing grounds are now high rise buildings. This has made children prefer indoor activities and indoor games instead of the outdoor games and activities [20].

The prevalence of myopia was found to increase with the older class of the respondents, from being least prevalent in lower forms to the higher prevalence in Form Four class. This can be attributed to the educational pressures in upper classes that are Forms Three and Four [21]. This can be equated to the global trends that have found myopia to be highly prevalent in those that are involved with intensive near work activities [22]. Educational pressure has been shown to have a significant relationship with myopia [23], since in order to get good grades one has to study hard which involves a lot of near related activities that have been found to sometimes have an influence on myopia [24].

\section{CONCLUSION AND RECOMMENDATIONS}

The prevalence of myopia in this study was found to be $7.5 \%$ and was higher in males as compared to females. It was also found to be more prevalent in those aged 11-15 years of age. Most of those who were found to be affected were those from urban areas and the prevalence was higher in the upper school level classes compared to those in lower classes. Although there was no association between socio-demographic (gender, age, class of respondent and place of residence) with myopia the prevalence tends to demonstrate a clear increase with age.

It is recommended that further studies be conducted on other risk factors such as near work activities, the use of new technologies and increasing time spent indoors and how they may influence myopia

\section{Acknowledgements}

I take this opportunity to pass my appreciation to Masinde Muliro University of Science and Technology, particularly, the Department of Optometry and Vision Science - I am very grateful for the logistical support and opportunity given to me to undertake this academic endeavour. I acknowledge the contribution of research assistants.

\section{Authors' contributions}

This research was undertaken for the MSc in Optometry and Vision Science degree. A.R. was the project leader responsible for the experimental and project design under the supervision of M.B. and P.C.F. AR conducted the clinical research while M.B. and P.C.F. provided guidance on study design, methodology and research procedures. A.R. was responsible for the writing of this paper with support and editorial input from M.B. and P.C.F.

\section{Disclosures about a potential conflict of interests}

I declare that there is no conflict of interest in this study.

\section{REFERENCES}

1. Naidoo KS, Fricke TR, Frick KD, et al. Potential Lost Productivity Resulting from the Global Burden of Myopia: Systematic Review, Meta-analysis, and Modeling. Ophthalmology. 2019; 126(3): 338-346, doi: 10.1016/..ophtha.2018.10.029, indexed in Pubmed: 30342076. 
2. Bourne R, Flaxman SR, Braithwaite TB, et al. Vision Loss Expert Group of the Global Burden of Disease Study. Magnitude, temporal trends, and projections of the global prevalence of blindness and distance and near vision impairment: a systematic review and meta-analysis. Lancet Glob Health. 2017; 5(9): e888-e897, doi: 10.1016/S2214109X(17)30293-0, indexed in Pubmed: 28779882.

3. Bourne RRA, Stevens GA, White RA, et al. Vision Loss Expert Group. Causes of vision loss worldwide, 1990-2010: a systematic analysis. Lancet Glob Health. 2013; 1(6): e339-e349, doi: 10.1016/S2214109X(13)70113-X, indexed in Pubmed: 25104599.

4. Holden BA, Fricke TR, Wilson DA, et al. Global Prevalence of Myopia and High Myopia and Temporal Trends from 2000 through 2050. Ophthalmology. 2016; 123(5): 1036-1042, doi: 10.1016/j. ophtha.2016.01.006, indexed in Pubmed: 26875007.

5. Holden B, Sankaridurg P, Smith E, et al. Myopia, an underrated global challenge to vision: where the current data takes us on myopia control. Eye (Lond). 2014; 28(2): 142-146, doi: 10.1038/eye.2013.256, indexed in Pubmed: 24357836.

6. Pan CW, Ramamurthy D, Saw SM. Worldwide prevalence and risk factors for myopia. Ophthalmic Physiol Opt. 2012; 32(1): 3-16, doi: 10.1111/j. 1475-1313.2011.00884.x, indexed in Pubmed: 22150586.

7. Morgan PB, Efron N, Woods CA, et al. International Contact Lens Prescribing Survey Consortium. International survey of orthokeratology contact lens fitting. Cont Lens Anterior Eye. 2019; 42(4): 450-454, doi: 10.1016/j.clae.2018.11.005, indexed in Pubmed: 30448008.

8. Wong HB, Machin D, Tan SB, et al. Visual impairment and its impact on health-related quality of life in adolescents. Am J Ophthalmol. 2009; 147(3): 505-511.e1, doi: 10.1016/j.ajo.2008.09.025, indexed in Pubmed: 19056077.

9. Barasa E, Otieno S, Karimurio J. The prevalence and pattern of visual impairment and blindness among Primary School pupils in Kitale Municipality, Kenya. J Ophthalmol East Cent South African. 2013; October: $66-70$.

10. Nyamai LA. Prevalence, Knowledge, Attitude and Practice on Refractive error among Students attending Public High Schools in Nairobi County. Dep Ophthalmol. 2016; October: 109.

11. Bastawrous A, Mathenge W, Foster A, et al. Prevalence and predictors of refractive error and spectacle coverage in Nakuru, Kenya: a cross-sectional, population-based study. Int Ophthalmol. 2013; 33(5): 541-548, doi: 10.1007/s10792-013-9742-6, indexed in Pubmed: 23440405

12. Wedner SH, Ross DA, Balira R, et al. Prevalence of eye diseases in primary school children in a rural area of Tanzania. $\mathrm{Br} \mathrm{J}$ Ophthalmol. 2000; 84(11): 1291-1297, doi: 10.1136/bjo.84.11.1291, indexed in Pubmed: 11049957.
13. Nzuki HN. Significant refractive errors as seen in standard eight pupils attending public schools in Langata division. Nairobi 2004.

14. Rey-Rodríguez D, Álvarez-Peregrina C, Moreno-Montoya J. Prevalencia y factores asociados a miopía en jóvenes. Rev Mexic Oftalmol. 2017; 91(5): 223-228, doi: 10.1016/j.mexoft.2016.06.007.

15. Ho T, Nallasamy S. Myoia: Eidemiology and Strategies for Intervention. Vol. 2, Advances in Ohthalmology and Otometry. Elsevier Inc 2017: 63-74.

16. Morgan IG, Rose KA. Myopia: is the nature-nurture debate finally over? Clin Exp Optom. 2019; 102(1): 3-17, doi: 10.1111/cxo.12845, indexed in Pubmed: 30380590.

17. Ip J, Saw SM, Rose K, et al. Role of Near Work in Myopia: Findings in a Sample of Australian School Children. Invest Opthalmol Vis Sci. 2008; 49(7): 2903, doi: 10.1167/iovs.07-0804, indexed in Pubmed: 18579757.

18. Ip JM, Rose KA, Morgan IG, et al. Myopia and the urban environment: findings in a sample of 12-year-old Australian school children. Invest Ophthalmol Vis Sci. 2008; 49(9): 3858-3863, doi: 10.1167/iovs.071451, indexed in Pubmed: 18469186.

19. Hsu CC, Huang N, Lin PY, et al. Prevalence and risk factors for myopia in second-grade primary school children in Taipei: A population-based study. J Chin Med Assoc. 2016; 79(11): 625-632, doi: 10.1016/j. jcma.2016.02.011, indexed in Pubmed: 27349942.

20. You QiS, Wu LiJ, Duan JLi, et al. Factors associated with myopia in school children in China: the Beijing childhood eye study. PLoS One. 2012; 7(12): e52668, doi: 10.1371/journal.pone.0052668, indexed in Pubmed: 23300738.

21. Li SM, Li He, Li SY, et al. Anyang Childhood Eye Study Group. Time Outdoors and Myopia Progression Over 2 Years in Chinese Children: The Anyang Childhood Eye Study. Invest Ophthalmol Vis Sci. 2015; 56(8): 4734-4740, doi: 10.1167/iovs.14-15474, indexed in Pubmed: 26207310.

22. Sun JT, An M, Yan XBo, et al. Prevalence and Related Factors for Myopia in School-Aged Children in Qingdao. J Ophthalmol. 2018; 2018: 9781987, doi: 10.1155/2018/9781987, indexed in Pubmed: 29507811.

23. Bez D, Megreli J, Bez M, et al. Association Between Type of Educational System and Prevalence and Severity of Myopia Among Male Adolescents in Israel. JAMA Ophthalmol. 2019 [Epub ahead of print], doi: 10.1001/jamaophthalmol.2019.1415, indexed in Pubmed: 31145422.

24. Wu LJ, Wang YX, You QS, et al. Risk Factors of Myopic Shift among Primary School Children in Beijing, China: A Prospective Study. Int J Med Sci. 2015; 12(8): 633-638, doi: 10.7150/ijms.12133, indexed in Pubmed: 26283882. 